\title{
A construção identitária da Psicologia no Brasil: retratos da ditadura civil-militar brasileira
}

\author{
The Identity Construction of the Psychology in Brazil: Portraits of the \\ Brazilian Civil-Military Dictatorship.
}

Renan Vieira de Santana Rocha

Universidade Federal da Bahia

\section{RESUMO:}

O nascimento e o desenvolvimento da Psicologia Brasileira estão diretamente correlacionados com a época da Ditadura Civil-Militar Brasileira. Nesse sentido, este artigo, estruturado sob o formato de um ensaio teórico-crítico, objetiva analisar como os elementos próprios da Ditadura Civil-Militar Brasileira refletiram e influenciaram na construção da Psicologia, de suas instituições representativas e de suas práticas profissionais e políticas na realidade do Brasil, partindo de uma breve retomada histórica dos componentes que propiciaram a instauração do regime e das diferentes formas como o poder foi exercido pelas Forças Armadas e pelas elites econômicas da época, ressaltando também as características confluentes de todos os campos de análise apresentados. Para tanto, o texto se estrutura em três eixos centrais: (1) Histórico da Ditadura Civil-Militar Brasileira e alguns de seus Reflexos na Construção da Psicologia no Brasil; (2) Influências da Estrutura Ditatorial no Modus Operandi da Psicologia Brasileira; e (3) Arremates: Libertar as Práticas para Libertar os Sujeitos.

Palavras-chave: Psicologia; Ditadura; Organizações Profissionais.

\section{ABSTRACT:}

The birth and development of Brazilian Psychology are directly correlated with the time of the Brazilian Civil-Military Dictatorship. In this sense, this article, structured in the form of a theoretical-critical essay, aims to analyze how the elements of the Brazilian Civil-Military Dictatorship reflected and influenced the construction of Psychology, its representative institutions and its professional and political practices in the reality of Brazil, starting from a brief historical review of the components that led to the establishment of the regime and the different ways in which power was exercised by the Armed Forces and the economic elites of the time, also highlighting the confluent characteristics of all the fields of analysis presented. Therefore, the text is structured in three central axes: (1) History of the Brazilian Civil-Military Dictatorship and some of its Reflections on the Construction of Psychology in Brazil; (2) Influences of the Dictatorial Structure on the Modus Operandi of Brazilian Psychology; and (3) Endings: Release Practices to Release Subjects.

Key-words: Psychology; Dictatorship; Professional Organizations. 


\section{Introdução}

A regulamentação do exercício profissional da Psicologia no Brasil está diretamente associada a um passado histórico-político marcante no cenário brasileiro: a Ditadura Civil-Militar, regime autoritarista e militarista que esteve em voga no país entre os anos de 1964 e 1985. Dito isto, e ainda que a Lei Federal No N.119, de $^{\circ} 7$ de agosto de 1962, que efetivamente sanciona os cursos de formação e o exercício da profissão de psicóloga(o) no país, tenha sido assinada em período anterior ao formalmente compreendido pela Ditadura Civil-Militar, nossas práticas foram consolidadas paralelamente ao fortalecimento do próprio regime, situação que marca e demarca nosso percurso e desenvolvimento enquanto ciência e profissão - ao que poderíamos referenciar, por exemplo, o próprio surgimento do Sistema Conselhos de Psicologia do Brasil, que se dá a partir de 1973, com a publicação da Lei Federal No. 5.766, de 20 de dezembro de 1971.

Reconhecer esse percurso faz-se de suma importância para compreender como determinados modos de fazer da Psicologia se estruturaram no Brasil, e assim visualizar como se deu a construção identitária da própria Psicologia em nossa realidade nacional, o que foi superado e o que ainda se mantém como elemento de permanência histórica sentidos estes que subjazem ao objetivo principal deste artigo, qual seja o de analisar como os elementos próprios da Ditadura Civil-Militar Brasileira refletiram e influenciaram na construção da Psicologia, de suas instituições representativas e de suas práticas profissionais e políticas na realidade do Brasil.

Nessa direção, este texto se propõe como um estudo no formato de ensaio teóricocrítico (Cf. MENEGHETTI, 2011), intertextualizando-se em diálogo com outras autoras e autores importantes para a Psicologia Brasileira, e subdivide-se em três eixos centrais, que serão desenvolvidos logo a seguir: (1) Histórico da Ditadura Civil-Militar Brasileira e alguns de seus Reflexos na Construção da Psicologia no Brasil; (2) Influências da Estrutura Ditatorial no Modus Operandi da Psicologia Brasileira; e (3) Arremates: Libertar as Práticas para Libertar os Sujeitos. 


\section{Histórico da Ditadura Civil-Militar Brasileira e alguns de seus Reflexos na Construção da Psicologia no Brasil}

A Ditadura Civil-Militar Brasileira instaura-se a partir da destituição do expresidente João Goulart, em abril de 1964. Deste momento, iniciou-se no Brasil um regime autoritarista e militarista que viria a se estender até 1985, com a posse do então presidente José Sarney (Cf. PETIT; CUÉLLAR, 2012). No transcurso dessas duas décadas em que as Forças Armadas brasileiras foram responsáveis pela condução da maioria dos processos administrativos, políticos e econômicos no Brasil, uma série de outras ordens da vida social foi afetada, inclusive as que tangem aos exercícios profissionais das mais diversas categorias (Cf. MATTOS, 2009; VASCONCELOS, 2009).

Essa posição de controle assumida pelas Forças Armadas diz respeito às influências do período histórico imediato que antecedeu (e motivou) a instauração de diversas ditaduras militares em vários países da América Latina, como nos diz Quadrat (2012):

A segunda metade do século XX pode ser apontada como um período de enfrentamento e lutas políticas, especialmente entre os anos 1960 e 1980, no Cone Sul da América Latina. As ditaduras marcaram a trajetória do Paraguai (1954), Brasil (1964), Argentina (1966 e 1976), Uruguai (1973) e Chile (1973). [...] Com o término da Segunda Guerra Mundial e o início da Guerra Fria, ocorreram transformações importantes nas Forças Armadas latino-americanas, que pouco a pouco abandonaram o caráter nacional assumindo uma postura internacionalista de combate à 'subversão' (p. 20).

Dessa mudança de perspectiva, no recorte brasileiro, nota-se que a postura dos militares se amplia à dimensão de "gestão" e "direcionamento" do país, noções que se associam diretamente à questão da "segurança nacional" - inerente ao pensamento militar. A partir disto, fica nas mãos do governo - Forças Armadas - a condução generalizada de todos os sistemas públicos, preconizando um desenvolvimento nacional "livre" de todas as formas de "subversão" ao ideal "comunista" que poderia "assolar" a nação. E Quadrat (2012) segue:

A nova conduta militar seria marcada por um alto grau de politização, pelo incentivo à percepção de que havia a capacidade de intervenção política nos destinos do país e pelo abandono da ideia de 'intervenção cirúrgica'. Ou seja, com a doutrina da segurança nacional, os integrantes das Forças Armadas passaram a se ver como militares e ao mesmo tempo administradores, e a questão do desenvolvimento do país passou a estar intimamente ligada à segurança (p. 21). 
Todavia, haveremos de perceber que essa forma de gerir o país por parte das Forças Armadas, pautada em critérios aparentemente tão bem correlacionados, não terá surgido apenas alicerçada na defesa dos interesses nacionais, sob a égide da segurança nacional. Antes, trata-se também da manutenção de um certo modo de ordem social, pautado na dimensão (ainda presente) da produção de capital financeiro e do seu subsequente e consequente acúmulo.

O Brasil, no bojo das transformações sociais do governo de Juscelino Kubitschek, e sob forte influência dos processos que estavam ocorrendo nos mais diversos locais a nível internacional (com destaque para o surgimento/crescimento das ideologias comunistas), também viu surgir no seio de sua sociedade movimentos populares questionando o status quo vigente e preponderante que pautava as nossas relações de trabalho - e, assim podemos dizer, de exploração-dominação-opressão. Na contrapartida, as elites dominantes também se organizaram, como forma de preparar-se e defender-se dos questionamentos que começavam a se fortalecer. Sobre isso, é Saviani (2008) quem nos diz que: "Na medida em que se ampliava a mobilização popular pelas reformas de base, com as Ligas Camponesas no meio rural”, e, no meio urbano, com “[...] os sindicatos de operários nas cidades, as organizações dos estudantes secundaristas e universitários e os movimentos de cultura e educação popular, mobilizou-se também a classe empresarial" (p. 293).

Essa mobilização, por sua vez, não se deu de forma dissociada de outros setores sociais que já visavam um exercício de controle da nação: a classe empresarial encontrou nas Forças Armadas o amparo necessário à manutenção da ordem social vigente ${ }^{1}$. Dessas articulações, vemos que surgiram instituições que escancararam não apenas essas parcerias, mas também as suas formas de controlar e agir no seio da vida pública e social, como segue nos apresentando Saviani (2008):

Surgiu, então, em maio de 1959, o Instituto Brasileiro de Ação Democrática (IBAD), a primeira organização empresarial especificamente voltada para a ação política. Sua finalidade explícita era combater o comunismo e aquilo que seus membros chamavam de 'estilo populista de Juscelino'. Em 29 de Novembro de 1961, foi fundado o Instituto de Estudos Políticos e Sociais (IPES) por um grupo de empresários do Rio e de São Paulo, articulados com empresários multinacionais [...], por intermédio dos generais Heitor de Almeida Herrera e Golbery do Couto e Silva. [...] Enquanto o IBAD foi dissolvido pela justiça em dezembro de 1963, o IPES permaneceu em atividade por aproximadamente dez anos, até se autodissolver em junho de 1971 (p. 293-294).

Ainda segundo o autor, o IPES, a partir de sua fundação e durante todo o transcurso de seu funcionamento, atuou na direção de disciplinar a população, produzindo 
uma espécie de "guerra psicológica", que fragilizasse os movimentos de base popular e, por consequência, a própria defesa dos interesses populares. Isto se deu a partir de um forte controle midiático, mas também de uma articulação com diversos setores sociais que pudessem fazer penetrar no seio destes movimentos as noções interessantes às classes dominantes que seguiam se organizando (empresários e militares). Desse processo, temos como conclusão o Golpe Militar de 1964, e a leitura de que esta estratégia não teve como horizonte apenas um posicionamento militar, mas também uma poderosa ideologia capitalista e mercadológica, considerando-se que a "articulação entre os empresários e os militares conduziu ao golpe civil-militar desencadeado em 31 de março e consumado em $1^{\text { }}$ de abril de 1964”, e que, decorrente deste fato histórico, “[...] saíram vitoriosas, portanto, as forças socioeconômicas dominantes, o que implicou a adequação da ideologia política ao modelo econômico" (SAVIANI, 2008: 294).

Dito isto, algumas novas considerações se apresentam (Cf. CODATO, 2005). Primeiro, há o reconhecimento de que a ditadura tem em seu bojo um forte caráter econômico, que encontra forças para se fazer vigente não apenas nos velhos mecanismos alienantes de dominação popular, mas também na truculência e na forte repressão do sistema autoritarista militar. E, segundo, que esse processo produziu um intenso exercício de controle interno da nação, como recurso que dava conta dos anseios militaristas - de manter a ordem social e a segurança nacional - e dos anseios das elites econômicas - de manter o status quo vigente, a exploração de classe e a "segurança financeira". Tendo, assim, a parceria das elites capitalistas dominantes, que se legitimavam no poder financeiro, as Forças Armadas, por sua vez, se asseguravam no controle de "tudo" e de “todos", legitimando-se no poder político. Destarte, em diálogo com Codato (2005), diznos Quadrat (2012) que "se até então as Forças Armadas estavam voltadas para a defesa das fronteiras, com o novo contexto histórico mundial e diante da 'ameaça comunista', ocorreu a internalização do conceito de inimigo". Logo, “[...] para conter o avanço desse 'inimigo' e se manter no poder, os militares procuraram exercer um excessivo controle na vida da sociedade civil" (QUADRAT, 2012: 22).

E sobre este processo, se o compararmos com o que vinha sendo construído no governo de Juscelino Kubitschek, com sua política nacional-desenvolvimentista, veremos que a instauração da Ditadura Civil-Militar Brasileira, por fim, certamente não se alicerçou unicamente a partir de um cunho militarista, mas para frear o avanço de perspectivas que escapassem do capitalismo em suas bases predatórias/selvagens mais 
comuns (Cf. MARTINS FILHO, 2003); assim (com o perdão do jogo de palavras), costurando o que agora poderemos nominar como uma Ditadura Civil-MilitarEconômica $^{2}$, fato de nossa história que apresenta marcas profundas quanto aos modelo de desenvolvimento econômico brasileiro e à própria memória histórica e cultural do país até os dias atuais, e que sempre se revela em momentos onde, parece-nos, flertamos com ares mais progressistas em nossas políticas (Cf. STOTZ, 1986; GONÇALVES, 2013).

Sobre o impacto de tal fato, e sua presença na historiografia brasileira, vale ainda destacar o que Saviani nos diz:

Em consequência, o nacionalismo desenvolvimentista foi substituído pela doutrina da interdependência. Consumou-se, desse modo, uma ruptura política, considerada necessária para preservar a ordem socioeconômica, pois se temia que a persistência dos grupos que então controlavam o poder político formal viesse a provocar uma ruptura no plano socioeconômico. Portanto, se a 'Revolução de 1964' foi realizada para assegurar a continuidade da ordem socioeconômica, é inegável seu significado de 'mudança política radical', atestada até mesmo pelo simples fato da permanência dos militares no poder por 21 anos, caso inédito na história política brasileira (SAVIANI, 2008: 294).

Feita toda esta trajetória histórica, fica a questão: em que passo tudo isto se relaciona com a regulamentação e com a consolidação da Psicologia e suas estruturas de base no Brasil? E poderemos, em sequência, pensar em dois exemplos históricos para elucidar tal questão.

Primeiro, precisamos voltar nossos olhos para os processos educativos, que formam e capacitam ( a priori) as/os profissionais que virão a exercer a Psicologia, bem como tantas outras áreas do conhecimento. O período da Ditadura, dadas as suas estratégias de controle já evidenciadas neste texto, contribuiu para um engessamento dos modelos educacionais, impondo-lhes um determinado rigor disciplinar - rigor este que sempre pode/deve conter justificativas para todo o tipo de discriminação. Além disso, pelo viés econômico, Saviani (2008) nos explicita que umas das principais marcas deixadas como legado desta época à educação (não só a básica, mas também a superior) foi a "vinculação da educação pública aos interesses e necessidades do mercado" elemento de permanência histórica na formação e na práxis da Psicologia, mesmo nos dias atuais (Cf. BOCK, 1997; BOCK, 1999; COIMBRA, 2000; COIMBRA, 2001; COIMBRA; NASCIMENTO, 2001; COSTA; COIMBRA, 2008; COIMBRA; LOBO; NASCIMENTO, 2008; COIMBRA, 2011) ${ }^{3}$.

Neste mesmo sentido, em um segundo exemplo, vemos discretamente as marcas da estrutura disciplinar militarista dentro de algumas resoluções que direcionam a ação 
do Sistema Conselhos de Psicologia do Brasil ${ }^{4}$, a exemplo do Manual Unificado de Orientação e Fiscalização - MUORF (documento anexo à Resolução CFP No. 19/2000), onde se diz que: "Os Conselhos Federal e Regionais de Psicologia têm como principal função orientar, fiscalizar e disciplinar o exercício da profissão de psicólogo, em obediência ao que dispõe a Lei Federal No. 5.766, de 20 de dezembro de 1971" (CFP, $2000)^{5}$.

Ainda que durante o restante do documento as expressões que permaneçam de forma mais presente sejam "orientar" e "fiscalizar", a expressão "disciplinar" aparece como um dos três verbos principais a direcionar as ações, logo no princípio do texto. $\mathrm{E}$ mesmo que este termo possa ser encarado por diferentes vieses interpretativos, fica difícil desassociá-lo de uma influência dos ideais militaristas, onde a "ordem" e a "disciplina" apresentam-se como pontos de extrema relevância - e que cujas garantias assistem ao Sistema Conselhos de Psicologia do Brasil, enquanto "tribunal de ética" das psicólogas e psicólogos brasileiros, conforme dispõe a Lei Federal N $\mathrm{N}^{\circ}$. 5.766, de 20 de dezembro de 1971, já citada anteriormente.

Observemos, desta feita, novamente o que nos diz Saviani (2008):

Controlando com mão de ferro, pelo exercício do poder político, o conjunto da sociedade brasileira ao longo de duas décadas, o regime militar deixou um oneroso legado cujos efeitos continuam afetando a situação social do país nos dias de hoje. Faz sentido, pois, retomar a política educacional e as realizações da Ditadura Militar no Brasil, pondo em destaque aspectos que se fazem presentes, ainda hoje, na educação brasileira (p. 294-295).

Logo, a partir destes dois breves (porém, significativos) exemplos, e considerando as afirmações do autor quanto à educação como um parâmetro analítico para outras dimensões, nos é lícito e autorizado conjeturar que a Ditadura Civil-Militar Brasileira possa ter deixado algumas de suas marcas na construção e na história da Psicologia em nosso país, se compreendermos que os processos educativos/formativos e os processos fiscalizatórios operam a manutenção de um certo modo de fazer e pensar a Psicologia; e, por consequência, nos levam à afirmação de que essas marcas precisam ser enxergadas, pautadas e questionadas, se queremos produzir um efetivo rompimento com os modos de fazer herdados deste período histórico e seu respectivo regime político-econômico.

Por sua relevância, seguiremos avançando nestas análises no subtópico que será desenvolvido a seguir.

\section{Influências da Estrutura Ditatorial no Modus Operandi da Psicologia Brasileira}


Como já foi dito, a Ditadura Civil-Militar Brasileira deixou suas marcas em várias esferas da organização política do país. E, como não poderia deixar de ser, a consolidação da Psicologia também sofreu influências, não apenas enquanto ciência e profissão, mas enquanto campo político de articulação profissional.

Para ilustrar e trazer à tona argumentos que nos permitam comprovar essas influências, é preciso retomar a história que conduziu ao surgimento de dois importantes espaços de articulação e ordenamento do exercício profissional da Psicologia no Brasil: os Conselhos Federal e Regionais de Psicologia (CFP e CRPs) e o Sindicato de Psicólogos do Estado de São Paulo (SPESP) ${ }^{6}$.

Ainda que a Lei Federal № 4.119 tenha sido aprovada em 1962, apenas em 1973 é que efetivamente passa a funcionar o Conselho Federal de Psicologia (CFP). E este surgimento se dá não apenas dentro do contexto da Ditadura Civil-Militar, mas também após a instauração do AI-5 (Ato Institucional №. 5), um dos pontos ápices da repressão exercida pelas Forças Armadas no período referido. Sobre isto, é Hur (2012) quem nos traz importantes contribuições:“A Lei 4.119/62 é fruto de uma mobilização da década de 1950, contudo os psicólogos apenas voltaram a se mobilizar para instituir os conselhos em 1969, após o Ato Institucional № 5 - AI-5 -, num momento de acirramento da repressão política no país, na época em que a violência do Estado foi a mais intensa na história brasileira" (p. 74).

Segundo o autor, é curioso pensar sobre este momento, posto que é dentro de um contexto de intensa repressão que esta classe se organiza e se consolida institucional e burocraticamente - ou seja, associada aos dispositivos estatais de controle e disciplinamento, apartada de maiores contribuições dos movimentos sociais e das classes populares em geral. Diz-nos ele que:

[...] contraditoriamente, é nesse período ditatorial que os psicólogos se organizam para criar os conselhos; os psicólogos voltam a se reorganizar justamente quando há um refluxo e uma intensa repressão aos movimentos sociais". Isto, por conseguinte, nos levará ao vislumbre de que: "A organização dos psicólogos não foi feita como um movimento social, reivindicador, e sim numa ação institucionalizada, direta, com os representantes do Estado da ditadura (HUR, 2012: 74).

Disto, temos que toda e qualquer ação política que viesse a ser produzida pelos profissionais da Psicologia estaria sob o julgo das Forças Armadas e seus dispositivos de controle, posicionando a classe ao lado do Estado e seus ímpetos repressores. Como consequência, o Sindicato, que deveria ser a principal instituição de defesa dos direitos 
das(os) psicólogas(os) no Brasil, surge amplamente atrelado e "cúmplice" do governo ditatorial, em notória negociata:

[...] se a categoria queria ter seus conselhos, ela deveria primeiro mostrar que está organizada, ou seja, antes de assumir o Conselho, organizar o Sindicato. Então, os psicólogos deveriam criar um Sindicato atrelado ao Estado da ditadura para mostrar que a categoria estava 'organizada' e consequentemente não representaria um perigo político para o regime instituído. Provavelmente, o interesse do Governo militar não era ver a categoria organizada, mas sim ter uma categoria profissional atrelada a seus interesses políticos e que não iria se constituir como inimiga de seu Governo opressivo. Então, após tal organização, teria o direito de ter a Lei do Conselho Profissional aprovada (HUR, 2012: 74).

Esse contexto de criação de ambas as instituições produziu marcas que repercutiram em uma formulação de fazer psicológico que esteve completamente desatrelado de vieses ético-políticos, questionadores ou mesmo vinculados à análise de problemas sociais como fatores condicionantes para a produção de sofrimento psíquico (Cf. SCARPARO; TORRES; ECKER, 2014). A Psicologia se afirmava no lugar da profissão, do trabalho, e não da política - ainda que para atender a seus próprios interesses de classe. Ao nível dos Conselhos Regionais, por exemplo, veremos que:

O CRP tinha como objetivos a fiscalização e a disciplinarização do exercício profissional, enquanto a entidade sindical a representação dos psicólogos. Entretanto, mesmo com atribuições distintas, em que uma aparece como instituição disciplinar do Estado e a outra, como representação dos psicólogos, tiveram uma atuação conjunta. Praticamente compuseram um mesmo grupo e assumiram práticas eminentemente corporativistas, em que operaram uma cisão explícita entre a atuação profissional e política; sempre afirmaram que a própria atuação era ligada à profissão e não à política (SCARPARO; TORRES; ECKER, 2014: 75).

Aqui, convém estabelecer uma necessária salvaguarda: muito embora teçamos considerações, sobretudo, voltadas para as principais instituições representativas da Psicologia no Brasil, convém salientar que estas não podem soar como mimetismo de toda a expressão da classe psicológica nacional. Nas Universidades, exempli gratia, já é possível observar a produção de um pensamento crítico em Psicologia, de criação de projetos comprometidos com as classes populares e de resistência ao governo ditatorial, já de há bastante tempo. Destaque-se, exemplificativamente, os trabalhos que analisam a Psicologia Social brasileira, publicados por autores como Leonardo Pinto de Almeida e Maria do Carmo Guedes. A partir da década de 1970, as perspectivas críticas da Psicologia Social, muito preocupadas com os problemas concretos da realidade brasileira, começam a emergir na Psicologia. Nesse sentido, se é verdade que poderia haver um forte setor da Psicologia desatrelado a vieses políticos, como estamos aqui a discorrer, por 
outro lado, é necessária uma contumaz cautela, que não nos conduza a uma perigosa generalização quanto ao todo da categoria profissional.

Salvaguarda feita, podemos retomar a análise quanto à construção dos Conselhos: e destaquemos o uso do termo "disciplinar", referido anteriormente quando citamos o Manual Unificado de Orientação e Fiscalização - MUORF, mas também presente em dispositivos legais da época, como a também já citada Lei Federal № 5.766/1971, como novamente exemplos analíticos para as instituições representativas em perspectiva (os conselhos e os sindicatos). Em todo o percurso apresentado, evidencia-se a constituição de todo um modelo formador disciplinar, como que adestrador da parcela populacional representada pelas(os) psicólogas(os). Constituía-se aí um núcleo apoiador do Estado e de suas ações, a serviço dos interesses das Forças Armadas e, por conseguinte, das elites econômicas dominantes - mantenedor, em última instância, do status quo vigente.

Nesse mesmo sentido, havia, portanto, uma desresponsabilização por questões relativas a violações aos Direitos Humanos - exploração dos trabalhadores, violência como recurso "pacificador", perseguições políticas, restrições à liberdade de expressão, etc. (Cf. SCARPARO; TORRES; ECKER, 2014) -, bem como um reconhecimento do Estado então vigente como parceiro/apoiador da classe profissional - o que se comprova pela concessão de diplomas de "psicólogo honorário" a alguns dos principais generais que comandaram o Brasil (Cf. HUR, 2012). Vide:

As associações trabalharam de forma corporativista, pela defesa e disciplinarização do exercício profissional, e mostraram proximidade com o regime militar, ao não participar de manifestações públicas críticas ao Estado, como a manifestação pelos direitos humanos em decorrência do assassinato do jornalista Wladimir Herzog, e concedendo o diploma de psicólogo honorário aos presidentes Médici e Geisel e seus ministros do Trabalho. Durante toda a década de 1970 as entidades de Psicologia mantiveram esse perfil de atuação, sendo instituição disciplinar atrelada ao regime militar (HUR, 2012: 83).

Frente ao que está aqui exposto, fica cada vez mais evidente o quanto a consolidação da Psicologia no Brasil esteve atrelada à Ditadura Civil-Militar Brasileira, não apenas como mais uma institucionalização que ocorre concomitantemente ao período histórico em voga, mas como reais apoiadores e legitimadores deste modelo de Estado situação que se apresentou durante toda a década de 1970. Não obstante, este movimento vai gradativamente encontrando seu fim na década de 1980, paralelamente ao processo de redemocratização do país e de questionamento sobre os ocorridos nos vintes anos que antecederam a transição política. Contudo, as marcas ditatoriais já estavam presentes e impressas em nossas práticas, repercutindo não apenas nos modos de gerir, defender e 
organizar a atuação da Psicologia, mas também na própria práxis psicológica, passada como nos apresentou Saviani (2008) - pelos ideais então presentes na própria educação e/ou formação profissional dos brasileiros, haja vista a já mencionada "vinculação da educação pública aos interesses e necessidades do mercado”. Assim, Hur (2012) conclui:

Consideramos que na década de 1970 as associações profissionais da Psicologia atuaram numa conformidade política ao Estado ditatorial, denotando o compromisso histórico da Psicologia com as elites sociais do país, enquanto na década de 1980 houve uma renovação dos seus membros, que passaram a ter uma visão mais crítica e politizada sobre o Estado e o exercício da Psicologia, lutando pela restituição da democracia e pela ampliação da participação política da sociedade, por um lado atualizando, assim, o imaginário da transformação social do país, mas, por outro, ainda mantendo o caráter disciplinar de instituição normalizadora (p. 84).

Poderíamos, a partir de tudo isto, questionar como essas influências ainda se fazem reverberar dentro da organização institucional e representativa da Psicologia no país. E a resposta virá precisamente do reconhecimento de que, assim como na Ditadura a opressão e a repressão nem sempre se faziam de forma escancarada, mas também de mecanismos que disfarçavam o estado de intensa violência que vigorava no país, ainda hoje se utilizam "maquiagens" para que não se perceba (consciente ou inconscientemente) os reflexos e as marcas atitudinais perpetrados deste período, mesmo que de modo não perceptível mesmo para aquelas e aqueles que conduzem tais instâncias, como nos diz Coimbra (2000): “Na década de 90, muitos aspectos de todo esse 'entulho' autoritário têm sido criticados e até mesmo superados, com relação aos aparatos de repressão, aos organismos de informação, à legislação repressiva e à justiça militar". Logo, ainda que reconheçamos os avanços nas questões acerca da Psicologia na relação com os Direitos Humanos e as Políticas Públicas nas pautas atuais de nossas entidades representativas, há uma lógica legal subjacente ao surgimento destas mesmas instituições que não pode ser desconsiderada, já que, “alguns [mecanismos] permanecem sendo utilizados, sob novas maquiagens, porém utilizando as mesmas estratégias” (p. 02).

Isto, inclusive e por vezes, mantém também o serviço que segue sendo prestado às elites econômicas dominantes, adaptadas às mudanças políticas de cada época subsequente, e que seguem, ainda, - de alguma forma, majoritariamente e discretamente - no comando de várias esferas de nossa vida social, como se vê em Monteiro, Coimbra e Mendonça Filho (2006):

Vale lembrar que, no Brasil, devido ao contexto autoritário, a luta se fez tendo como meta a conquista de um Estado Democrático de Direito, já que esta via aparecia como única possibilidade de enfrentamento dos poderes estabelecidos naquele momento. Não 
se percebeu que, neste mesmo período, novos modos de dominação global se impunham numa versão mais sutil: a ditadura de mercado (p. 10).

Em suma, toda essa conjuntura acaba por produzir na Psicologia brasileira uma série de elementos de permanência histórica. Primeiro, uma forte despolitização de classe (com salvaguardas, já citadas), que não vê uma atuação política como parte importante de sua atuação no sentido da minimização dos efeitos nocivos das desigualdades sociais e opressões à saúde, enquanto bem-estar biopsicossocial, da população em geral. Segundo, uma não implicação com o debate dos Direitos Humanos, atitude que, ainda que seja fortemente pautada pelas últimas gestões do Conselho Federal de Psicologia e da maioria dos Conselhos Regionais de Psicologia, não é assumida enquanto posição coesa por todo o segmento de psicólogas(os) brasileiras(os), ainda comprometidas(os) com a lógica de mercado que estigmatiza o pobre e reforça o poder do acúmulo de capital. E, terceiro, uma responsabilização do Sistema Conselhos de Psicologia do Brasil pela defesa dos interesses da categoria, deslocando para este funções que deveriam ter como atores principais os vários Sindicatos de Psicólogas(os) existentes no país - entidades estas que, por sua vez, carregam consigo os efeitos da despolitização da categoria profissional em questão, desacreditados quanto à sua possibilidade de defesa da categoria, que em mesma medida cobra atuação mais ignora estes como instâncias importantes ao fortalecimento dos direitos trabalhistas para a Psicologia (Cf. HUR; LACERDA JÚNIOR, 2014).

Em contrapartida, é preciso afirmar que estes elementos têm sido gradativamente desconstruídos, muito por conta da atuação que vemos por parte do Sistema Conselhos de Psicologia do Brasil, com destaque para o próprio Conselho Federal de Psicologia $(\mathrm{CFP})^{7}$.

\section{Arremates: Libertar as Práticas para Libertar os Sujeitos}

O Sistema Conselhos de Psicologia do Brasil, hoje, se apresenta como uma das principais organizações de classe profissional que atuam no sentido da garantia e luta pela efetivação do que está disposto na Declaração Universal dos Direitos Humanos (DUDH), bem como dos demais acordos que desembocam internacionalmente a partir deste documento. Estas ações falam do "novo compromisso social da Psicologia", formulação conceitual que agrega em si toda uma dimensão de direcionamentos que a Psicologia brasileira deve assumir para dar conta da defasagem histórica que se construiu frente à 
sua atuação outrora fortemente vinculada ao governo militarista, reaproximando-a dos movimentos sociais e das classes populares e seus dilemas. Sobre isto, Bock (1999) define e nos indica uma rota possível, que é: "Discutir o compromisso social da Psicologia significa, portanto, sermos capazes de avaliar a sua inserção, como ciência e profissão, na sociedade e apontarmos em que direção a Psicologia tem caminhado", e, destas considerações, levantar a nós, psicólogas e psicólogos, a questão: “[...] para a transformação das condições de vida? [Ou] Para a manutenção?” (p. 321).

Dizer isto é assumir que a Psicologia já ocupou o status de mantenedora de relações sociais opressoras, e que é preciso repensar esse percurso histórico, analisandoo e posicionando-nos sobre tal, para que disto construamos uma mudança orientada por este "novo compromisso social". Ao mesmo tempo, esta construção convoca-nos exatamente a discutir qual é este nosso compromisso social, se o temos assumido enquanto práxis dentro de todos os espaços de ocupação da Psicologia e se efetivamente vemos os frutos desta mobilização na melhoria das condições de vidas do povo que, via de regra, parcamente acessou o que é "ofertado" no leque de possibilidades da Psicologia.

Ao mesmo tempo, precisamos nos debruçar sobre esses condicionantes produtores de sofrimento que se fazem presentes no cotidiano das relações sociais de nosso país. Deslocar o nosso olhar clínico para as ruas e praças, tão simbólicas e proibidas na Ditadura Civil-Militar, mas que são verdadeiros espaços onde a vida se processa, e na vida, as opressões que se lhe fizeram "inerentes" e constantes. Perceber que a Psicologia tem sim um lugar político diante da concretude da vida coletiva, e que este lugar também fala da necessidade de agir para minimizar (ou, quiçá, erradicar) elementos de permanência histórica que sussurram a presença de uma Ditadura velada, tatuada nos modelos econômicos que ainda vigoram e ordenam o direcionamento deste país especialmente em um novo momento histórico em que a sanha do autoritarismo, diante de avanços progressistas conquistados nas últimas décadas, novamente volta a nos rodear. E isto, em fato, é um dos nossos grandes débitos e desafios modernos, como nos dizem tanto Martín-Baró (1996), quanto também Bock (1999), em que: "Identificar-se com as necessidades de nosso povo e acompanhar o movimento destas necessidades, sendo capazes de construirmos, sempre e permanentemente, respostas técnicas e científicas. É este o nosso desafio" (p. 328).

Tal desafio, ainda que permaneça nos tempos atuais, justifica uma série de ações assumidas pelo Conselho Federal de Psicologia e por uma grande parcela dos Conselhos 
Regionais, onde basta ver que tais instituições passaram a não só apoiar a pauta dos Direitos Humanos, como tornaram este um lema em suas gestões, ampliando a ação das Comissões de Direitos Humanos (atuando em áreas como gênero, relações raciais, emergências e desastres, educação, combate à homofobia, direitos da criança e da/o adolescente, uso de substâncias psicoativas, direitos das pessoas com deficiência, etc.), vitaminando o contato e a articulação com os movimentos sociais (a exemplo da luta em prol do Quilombo Rio dos Macacos, na Bahia, e dos povos indígenas da região de Belo Monte, no Pará, e das denúncias feitas contra os abusos cometidos nas comunidades terapêuticas para tratamento de usuários de drogas, em todo o país) e com o Movimento Estudantil de Psicologia, a nível regional Norte-Nordeste e a nível nacional. Tudo isto, inclusive, diz respeito a um processo de abertura dos espaços que foi intensamente produzida pela "chegada" da discussão sobre os Direitos Humanos em diferentes espaços da vida social, desde o contexto da segunda metade da Ditadura Civil-Militar.

No Brasil, a luta pelos direitos humanos emerge com força nos movimentos contra a ditadura militar. Surgem com os chamados novos movimentos sociais que se efetivam ainda na segunda metade dos anos 1970, com práticas que começaram a rechaçar os movimentos tradicionalmente instituídos e que politizaram o cotidiano nos locais de trabalho e moradia, inventando novas formas de fazer política (COIMBRA; LOBO; NASCIMENTO, 2008: 95).

Ao mesmo tempo, estas ações supramencionadas devem convocar a classe profissional a discutir junto, colaborar direta e concretamente com as diretrizes de atuação que virão a pautar os triênios que consecutivamente seguem assumindo a gestão do Sistema Conselhos de Psicologia no Brasil. Isto porque este espaço também foi outrora negado, exatamente pelo caráter disciplinar e fiscalizador preponderante que esteve estabelecido como resultado e retrato da Ditadura Civil-Militar. Nesse sentido, fortalecer espaços como os dos Congressos Regionais da Psicologia (COREPs) e do Congresso Nacional da Psicologia $(\mathrm{CNP})^{8}$ aparece como possibilidade promissora, ainda que inicialmente, de convite à participação direta, democratizando as vias de acesso aos órgãos reguladores da Psicologia Brasileira. Isso se costura com a própria necessidade de fortalecer a formação em Psicologia, pela via de uma cuidadosa seleção de temas emergentes e pertinentes à sociedade brasileira, e atualizando permanentemente o seu debate, a partir de instâncias dialógicas do Sistema Conselhos de Psicologia do Brasil, como mencionamos aqui. Isto porque “[...] é preciso uma formação de um profissional comprometido com o seu tempo e sua sociedade, que trabalhe na promoção de saúde desta comunidade", portanto, “[...] um profissional que discuta seu compromisso com a 
sociedade, um profissional que retire deste debate a finalidade social de seu trabalho; um profissional cidadão" (BOCK, 1997: 42).

Ademais, cabe ainda à Psicologia um de seus compromissos mais sérios: o para com a verdade que, por tanto tempo, esteve velada, mascarada e escondida nos porões da Ditadura. Não se trata aqui de um preciosismo do passado, ou mesmo de um ímpeto de estagnação no tempo - antes, trata-se de dar conta à justa reparação a quem de direito, aos tantos e tantas homens e mulheres que tiveram suas vidas e a de seus familiares dilaceradas pela repressão e pelos mecanismos de exercício de poder aplicados pelas Forças Armadas. E, para tal, primeiro é preciso reconhecer que seguimos com um (péssimo) legado histórico de que muito pouco ainda se faz para dar conta de punir àqueles que física, psíquica e moralmente torturaram centenas de pessoas. Sobre isto, diznos Coimbra (2000) que:

[...] apesar de todos esses dispositivos legais e jurídicos acoplados à 'segurança nacional', denúncias foram feitas nas auditorias militares pelos milhares de presos políticos, denúncias estas que estão oficialmente registradas nos Inquéritos Policiais Militares (IPMs). Levantou-se que 1.843 pessoas presas no período de 1964 a 1979 denunciaram torturas, mortes e desaparecimentos de opositores políticos. Chegou-se, ainda, ao número de 7.727 pessoas denunciadas pela Justiça Militar no período de 1964 até 1979. Daí, calcula-se que o número de presos seja mais alto, pois muitos não foram denunciados e nem sequer prestaram depoimentos em auditorias militares (COIMBRA, 2000: 15).

Tudo isto diz respeito ao "novo compromisso social da Psicologia". Tudo isto trata de uma reparação por anos de desserviço aos Direitos Humanos, às classes populares, aos movimentos sociais, aos pobres e estigmatizados do Brasil. Todavia, cabe-nos perguntar: tudo isto dá conta deste débito? Muito provavelmente não. Mas apresenta-se como pontapé inicial, como convite a repensar anos e anos de formação, teoria e prática, para fazer surgir novas(os) psicólogas(os), comprometidos com o bem-estar biopsicossocial de todo e qualquer cidadão brasileiro, independente de classe, raça, gênero, religião, sexualidade, etc. E tudo isto precisa estar articulado de forma coesa para toda a classe profissional. Pode parecer-nos impossível, em um primeiro olhar, acreditar que um dia tenhamos uma Psicologia socialmente referenciada, hegemonicamente pautada por um compromisso social libertário, em torno de pautas libertárias. Mas acreditar é essencial, para que possamos partir para um fazer que seja realmente diferente, inovador e (oxalá) revolucionário, pois, como nos diz Bock (1999), ainda nos primeiros anos da redemocratização do país, mas em afirmativas que muito pertinentemente cabem para os dias de hoje: "Estamos em um momento importante de construir planos, projetos para o 
futuro; projetos estes que percebemos claramente como definidores de nossa identidade profissional”. Destarte, “[...] estamos querendo definir quem queremos ser no próximo século. Pretensioso, sim, porém necessário e correto" (BOCK, 1999: 316).

Todavia, cabe também perguntar: estaríamos nós, psicólogas e psicólogos brasileiros, abertos a este convite, ou melhor, a esta convocação? Estaríamos nós dispostos a refletir sobre essa construção identitária da Psicologia, e a partir dela produzir mudanças concretas? Disto, cabe citar Martín-Baró (1996), ao refletir sobre a realidade centro-americana, mas cujas análises facilmente se aplicam à realidade de toda a América Latina:

Talvez a opção mais radical com que se defronta a psicologia centro-americana [e latino-americana] hoje esteja na alternativa entre uma acomodação a um sistema social que pessoalmente nos tem beneficiado, ou uma confrontação crítica frente a esse sistema. Em termos mais positivos, a opção reside entre aceitar, ou não, acompanhar as maiorias pobres e oprimidas em sua luta por constituir-se como povo novo em uma terra nova. Não se trata de abandonar a psicologia; trata-se de colocar o saber psicológico a serviço da construção de uma sociedade em que o bem estar dos menos não se faça sobre o mal estar dos mais, em que a realização de alguns não requeira a negação dos outros, em que o interesse de poucos não exija a desumanização de todos (MARTÍN-BARÓ, 1996: 23).

No fim, queremos defender que é preciso libertar as práticas para libertar os sujeitos. E possibilitar que a Psicologia, subjetivando-a e fazendo-a sujeito humano, possa olhar seu passado, encará-lo, assumi-lo, confrontá-lo e, após tal, ressignificar sua vida, seu porquê de existir. Para que assim, feito nova, possa estar diante dos homens e mulheres de nosso tempo, fazendo-se livre das amarras sociais que a oprimiram e oprimem, sem esquecer que essas opressões e que a sanha autoritarista permanecem aí, sempre à espreita. E assim, junto ao povo, fazer-se também povo.

\section{Referências}

BOCK, Ana Mercês Bahia. A Psicologia a caminho do novo século: identidade profissional e compromisso social. Estudos de Psicologia (Natal), Natal, v. 04, n. 02, p. 315-329, 1999. Disponível em: https://www.scielo.br/pdf/epsic/v4n2/a08v4n2. Acesso em: 24 Nov. 2020.

BOCK, Ana Mercês Bahia. Formação do psicólogo: um debate a partir do significado do fenômeno psicológico. Psicologia: Ciência e Profissão, Brasília, v. 17, n. 02, p. 37-42, 1997. Disponível em: https://www.scielo.br/pdf/pcp/v17n2/06.pdf. Acesso em: 24 Nov. 2020.

BRASIL. Lei Federal No. 4.119, de 27 de Agosto de 1962. Brasília (DF): Diário Oficial da União, 1962. Disponível em: https://www.planalto.gov.br/ccivil_03/leis/19501969/14119.htm. Acesso em: 23 Nov. 2020. 
BRASIL. Lei Federal No. 5.766, de 20 de Dezembro de 1971. Brasília (DF): Diário Oficial da União, 1971. Disponível em: https://www.planalto.gov.br/ccivil_03/leis/15766.htm. Acesso em: 23 Nov. 2020.

CODATO, Adriano Nervo. Uma História Política da Transição Brasileira: da Ditadura à Democracia. Revista Sociologia e Política, Curitiba, n. 25, p. 83-106, 2005. Disponível em: https://www.scielo.br/pdf/rsocp/n25/31113.pdf. Acesso em: 15 Abr. 2021.

COIMBRA, Cecília Maria Bouças. Doutrinas de segurança nacional: banalizando a violência. Psicologia em Estudo, Maringá, v. 05, n. 02, p. 01-22, 2000. Disponível em: https://www.scielo.br/pdf/pe/v5n2/v5n2a02.pdf. Acesso em: 25 Nov. 2020.

COIMBRA, Cecília Maria Bouças. Práticas de estranhamento, indignação e resistência. Psicologia USP, [S. 1.], v. 22, n. 03, p. 579-586, 2011. Disponível em: <https://www.revistas.usp.br/psicousp/article/view/42140>. Acesso em: 25 Nov. 2020.

COIMBRA, Cecília Maria Bouças; LOBO, Lilia Ferreira; NASCIMENTO, Maria Lívia do. Por uma invenção ética para os Direitos Humanos. Psicologia Clínica, Rio de Janeiro, v. 20, n. 02, p. 89-102, 2008. Disponível em: https://www.scielo.br/pdf/pc/v20n2/a07v20n2.pdf. Acesso em: 25 Nov. 2020.

COIMBRA, Cecilia Maria Bouças; NASCIMENTO, Maria Lívia do. O Efeito Foucault: Desnaturalizando Verdades, Superando Dicotomias. Psicologia: Teoria $e$ Pesquisa, Brasília, v. 17, n. 03, p. 245-248, 2001. Disponível em: https://www.scielo.br/pdf/ptp/v17n3/8814.pdf. Acesso em: 25 Nov. 2020.

COSTA, Eduardo Antonio de Pontes; COIMBRA, Cecília Maria Bouças. Nem criadores, nem criaturas: éramos todos devires na produção de diferentes saberes. Psicologia \& Sociedade, Porto Alegre, v. 20, n. 01, p. 125-133, 2008. Disponível em: https://www.scielo.br/pdf/psoc/v20n1/a14v20n1.pdf. Acesso em: 25 Nov. 2020.

CRUZ, Ana Vládia Holanda et al . A Ditadura que se Perpetua: Direitos Humanos e a Militarização da Questão Social. Psicol. Cienc. Prof., Brasília, v. 37, n. spe, p. 239-252, 2017 . Disponível em: $<$ http://www.scielo.br/scielo.php?script=sci_arttext\&pid=S141498932017000500239\&lng=en\&nrm=iso >. Acesso em: 15 Abr. 2021.

GONÇALVES, Reinaldo. Desenvolvimento às avessas: verdade, má-fé e ilusão no atual modelo brasileiro de desenvolvimento. Rio de Janeiro: LTC, 2013, p. 01-62.

HUR, Domenico Uhng. Políticas da psicologia: histórias e práticas das associações profissionais (CRP e SPESP) de São Paulo, entre a ditadura e a redemocratização do país. Psicologia USP, São Paulo, v. 23, n. 01, p. 69-90, 2012. Disponível em: https://www.scielo.br/pdf/pusp/v23n1/v23n1a04.pdf. Acesso em: 26 Nov. 2020.

HUR, Domenico Uhng; LACERDA JÚNIOR, Fernando. Psicologia e Democracia: da Ditadura Civil-Militar às Lutas pela Democratização do Presente. Psicologia: Ciência e Profissão, Brasília, v. 37, n. spe, p. 03-10, 2017. Disponível em: https://www.scielo.br/pdf/pcp/v37nspe/1414-9893-pcp-37-spe1-0003.pdf.

Acesso em: 15 Abr. 2021.

MARTIN-BARO, Ignácio. O Papel do Psicólogo. Estudos de Psicologia (Natal), Natal, v. $02, \quad$ n. $01, \quad$ p. 07-27, 1997. Disponível em: https://www.scielo.br/pdf/epsic/v2n1/a02v2n1.pdf. Acesso em: 26 Nov. 2020. 
MARTINS FILHO, João Roberto. Forças Armadas e política, 1945-1964: a ante-sala do golpe. In: FERREIRA, Jorge; DELGADO, Lucília de Almeida Neves (Orgs.). $O$ Brasil Republicano: O tempo da experiência democrática. Rio de Janeiro: Civilização Brasileira, 2003, p. 97-126.

MATTOS, Marcelo Badaró. Trabalhadores e Sindicatos no Brasil. São Paulo: Expressão Popular, 2009, p. 61-115.

MENEGHETTI, Francis Kanashiro. O que é um ensaio-teórico?. Revista de Administração Contemporânea, Curitiba, v. 15, n. 02, p. 320-332, 2011. Disponível em: https://www.scielo.br/pdf/rac/v15n2/v15n2a10.pdf. Acesso em: 23 Nov. 2020.

MONTEIRO, Ana; COIMBRA, Cecília; MENDONCA FILHO, Manoel. Estado democrático de direito e políticas públicas: estatal é necessariamente público?. Psicologia \& Sociedade, Porto Alegre, v. 18, n. 02, p. 7-12, 2006. Disponível em: https://www.scielo.br/pdf/psoc/v18n2/01.pdf. Acesso em: 25 Nov. 2020.

PETIT, Pere; CUÉLLAR, Jaime. O golpe de 1964 e a instauração da ditadura civil-militar no Pará: apoios e resistências. Estudos Históricos (Rio de Janeiro), Rio de Janeiro, v. 25, n. 49, p. 169-189, 2012. Disponível em: https://www.scielo.br/pdf/eh/v25n49/11.pdf. Acesso em: 23 Nov. 2020.

QUADRAT, Samantha Viz. A preparação dos agentes de informação e a ditadura civilmilitar no Brasil (1964-1985). Varia Historia, Belo Horizonte, v. 28, n. 47, p. 1941, 2012. Disponível em: https://www.scielo.br/pdf/vh/v28n47/02.pdf. Acesso em: 23 Nov. 2020.

SAVIANI, Dermeval. O legado educacional do regime militar. Cadernos CEDES, Campinas, v. 28, n. 76, p. 291-312, 2008. Disponível em: https://www.scielo.br/pdf/ccedes/v28n76/a02v2876.pdf. Acesso em: 23 Nov. 2020.

SCARPARO, Helena Beatriz Kochenborger; TORRES, Samantha; ECKER, Daniel Dall'Igna. Psicologia e Ditadura Civil-Militar: reflexões sobre práticas psicológicas frente às violências de estado. Revista EPOS, Rio de Janeiro, v. 05, n. $01, \quad$ p. 57-78, 2014. Disponível em: http://pepsic.bvsalud.org/pdf/epos/v5n1/04.pdf. Acesso em: 15 Abr. 2021.

STOTZ, Eduardo Navarro. As faces do moderno Leviatã. In: STOTZ, Eduardo Navarro; MELLO, Maria Amélia (Orgs.). Vinte anos de resistência: alternativas da cultura no regime militar. Rio de Janeiro: Espaço e tempo, 1986, p. 13-28.

VASCONCELOS, Cláudio Beserra de. As análises da memória militar sobre a ditadura: balanço e possibilidades. Estudos Históricos (Rio de Janeiro), Rio de Janeiro, v. 22, n. 43, p. 65-84, 2009. Disponível em: https://www.scielo.br/pdf/eh/v22n43/v22n43a04.pdf. Acesso em: 27 Nov. 2020.

Renan Vieira de Santana Rocha. Psicólogo Sanitarista (UFBA). Mestre e Doutorando em Saúde Coletiva (UFBA). Especialista em Saúde Coletiva (UFBA), em Gestão em Saúde (UNEB) e em Estudos Étnicos e Raciais (IFBA). Docente da Universidade Cruzeiro do Sul (UNICSUL) e da 


\title{
Faculdade Latino-Americana de Ciências Sociais (FLACSO). Presidente do Conselho Regional de Psicologia da Bahia (CRP-03), entre os anos de 2019 e 2021.
}

E-mail: renanvsr@gmail.com

\begin{abstract}
1 Aqui, cremos caber uma ponderação: é fato notório que os dois setores em questão foram muito importantes para o golpe de 1964, mas deve-se somar à classe empresarial os setores da classe média que viram nos militares uma oportunidade de "salvação". Um rápido exemplo disso foi a "Marcha da Família com Deus pela Liberdade", ocorrida em 1964. Nesse sentido, não se trata exclusivamente do povo, de um lado, e das elites, de outro. Havia uma pluralidade no próprio tecido social que apoiou o golpe militar, e a dicotomia acaba por expressar, muito mais, um fenômeno que é complexo: a própria luta de classes.
\end{abstract}

${ }^{2}$ Conforme se verá no texto de Cruz e colaboradoras (2017), a nomenclatura atual para se referir ao período histórico em questão varia, conforme diferentes acepções da literatura científica. No estudo citado, por exemplo, veremos que alguns autores e órgãos preferem a expressão "Ditadura Empresarial-Militar". Contudo, em consonância ao que dispõem documentos públicos e campanhas movidas pelo Conselho Federal de Psicologia (CFP), neste artigo, optamos pelo uso da expressão "Ditadura Civil-Militar", intentando evidenciar os diferentes setores do tecido social que contribuíram com as lógicas autoritaristas, em nível político e econômico, que imperaram no período da história brasileira aqui analisado.

${ }^{3}$ Convém salientar, contudo e em tempo, que o "casamento" entre educação e "necessidades do mercado", aqui sinalizado, já era uma "tendência" na Psicologia desde as décadas de 1920 e 1930, não sendo simplesmente um produto direto da Ditadura Civil-Militar; mas sim agravado e alargado por ela.

${ }^{4}$ Em tempo, vale dizer que estas influências não determinam uma ação intransigente e/ou autoritária por
parte desta instituição. Todavia, não se pode negar que estes reflexos existam, e que ainda se apresentem,
por vezes de forma sinuosa, nos documentos e diretrizes que pautam, direcionam e orientam a nossa
atuação, bem como a de nossas instituições representativas.

${ }^{5}$ O MUORF, como citado, é dos anos 2000, portanto, de um pouco depois da redemocratização do país. Não obstante, convém ressaltar que a própria Lei Federal No. 5.766/1971, bastante anterior ao MUORF, criada bem nos "anos de chumbo" da ditadura, já prevê a disciplinarização do exercício profissional como horizonte, em nítida influência dos ideais ditatoriais. Nela, vale destacar o artigo $9^{\circ}$, que dispõe sobre as atribuições dos Conselhos Regionais e do Conselho Federal de Psicologia, onde se diz que: "São atribuições dos Conselhos Regionais: (...) b) orientar, disciplinar e fiscalizar o exercício da profissão em sua área de competência". Além deste tópico, em que destaca-se a noção da "disciplina", vê-se que esta está bastante presente também quando se trata das "infrações disciplinares". Há, nestas, inclusive, a noção de "Censura Pública", aplicada em caso de algumas infrações, outra nomenclatura que pode fortalecer a argumentação aqui presente. Dito isto, seria possível inferir (sempre com a devida cautela) que o MUORF teria, então, "quase-que-herdado" os ideais ditatoriais que estamos, aqui, a apontar.

${ }^{6}$ Para a construção desta parte do artigo, foram encontradas poucas referências teóricas que abordassem especificamente as influências da Ditadura Civil-Militar Brasileira na organização política/institucional das grandes instituições formais e representativas da Psicologia no país. Posto isto, parte do que será aqui apresentado diz respeito a um recorte do estado de São Paulo, apresentado no texto de Hur (2012), mas que ensejamos assumir como parâmetro analítico para a realidade brasileira. Registre-se, adicionalmente, que isto não impedirá a realização de parâmetros e conexões com outros estudos, como se verá junto ao texto de Scarparo, Torres e Ecker (2014).

7 Apesar da obduração destas últimas acepções, compreendemos que a relativa causalidade entre os processos históricos do autoritarismo e a despolitização da categoria não pode ser tomada de forma hegemônica ou mesmo plenamente generalizante. Caber-nos-ia, por exemplo, também afirmar a politização dos conselhos profissionais, dos sujeitos, psicólogas e psicólogos, apesar do autoritarismo. Notemos: muito embora vejamos, já há alguns anos, nos Conselhos Federal e Regionais de Psicologia, a organização política, em forma de candidaturas, de chapas que defendem pautas conservadoras e, inclusive, a chamada "cura gay", esse movimento não encontra lastro na maioria das psicólogas e psicólogos que, a despeito de afiliações em específico, têm elegido grupos políticos de perspectiva mais progressista e de franco posicionamento contra quaisquer perspectivas autoritaristas no país. Assim, ao passo em que afirmamos 
uma certa despolitização histórica da categoria, seria também injusto estender tal afirmação à plena totalidade da psicologia brasileira. Outrossim, é igualmente urgente destacar que não queremos, frente à análise de tons historiográficos que aqui se desenha, assumir o papel de "juízes", responsabilizando a geração de 70 e 80 por "não darem atenção" que julgamos, hoje, adequado, frente às questões que são caras para os que vivem no século XXI. É importante registrar que esta nossa análise não intenta cair em um tom de que "o presente é sempre melhor", tom este que positivaria o período em que se vive, ignorando todos os ataques estruturais aos Direitos Humanos e os resquícios ditatoriais que se assanham nos tempos de agora; mas, sim, intenta compreender criticamente as ações e os movimentos da classe de psicólogos nas suas respectivas épocas, em suas potências e limitações.

${ }^{8}$ Os Congressos Regionais (COREPs) e Nacional (CNP) da Psicologia são espaços decisórios que ocorrem a cada três anos, sempre nos anos eleitorais do Sistema Conselhos de Psicologia do Brasil, em que psicólogas e psicólogos reunidos em etapas municipais, estaduais e, por fim, nacional, indicam o que desejam, na forma de propostas, para os rumos da Psicologia no país, ao longo do próximo triênio, e servem como horizonte para as gestões dos Conselhos balizarem seus planejamentos e suas ações cotidianas. 